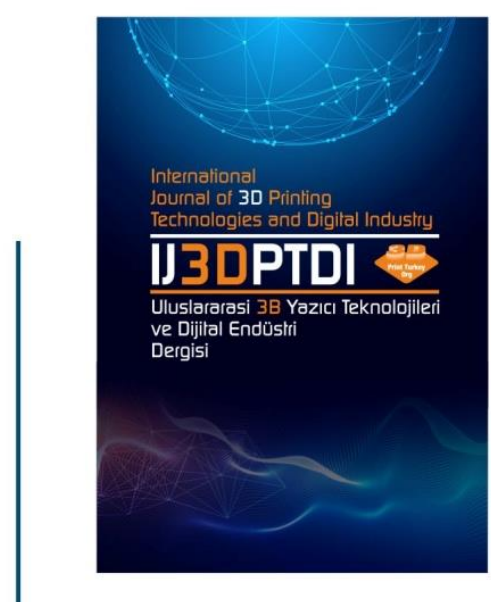

ULUSLARARASI 3B YAZICI TEKNOLOJILERI

VE DIJITAL ENDÜSTRI DERGISI

INTERNATIONAL JOURNAL QF 30 PRINTING TECHNOLOGIES AND DIGITAL INDUSTRY

ISSN:2602-3350 [Online]

URL: https://dergipark.org.tr/ij3dptdi

\title{
DESIGN AND PRODUCTION OF MULTI MATERIAL 3D PRINTER FOR SOFT ROBOTIC STRUCTURAL ELEMENTS
}

Yazarlar (Authors): Özgün Selvi*iD, Murat Yetim ${ }^{(D)}$, Samed Yiğit Çırnık ${ }^{(D)}$ Hasan Fehmi Illter ${ }^{\mathbb{D}}$, Muhammed Enes Akan ${ }^{\mathbb{D}}$, Temel Tomaç ${ }^{\mathbb{D}}$

Bu makaleye şu şekilde atıfta bulunabilirsiniz (To cite to this article): Selvi Ö., Yetim M., Çırnık S.Y., Ilter H.F., Akan M.E., Tomaç T. "Design and Production of Multi Material 3D Printer For Soft Robotic Structural Elements" Int. J. of 3D Printing Tech. Dig. Ind., 5(2): 227-236, (2021). 


\title{
DESIGN AND PRODUCTION OF MULTI MATERIAL 3D PRINTER FOR SOFT ROBOTIC STRUCTURAL ELEMENTS
}

\author{
Özgün Selvi*iD, Murat Yetim ${ }^{(i D}$, Samed Yiğit Çırnık \\ Hasan Fehmi İlter iD, Muhammed Enes Akan iD, Temel Tomaç iD \\ *Çankaya University, Engineering Faculty, Mechanical Engineering Department, Ankara, TURKEY \\ *Corresponding Author: ozgunselvi@cankaya.edu.tr
}

(Received: 21.06.2021; Revised: 15.07.2021; Accepted: 11.08.2021)

\begin{abstract}
With the latest technology, the development and interest in soft robots have gained speed. Flexible robots are generally produced by the casting method. This traditional production method has difficulties in the production of complex geometries such as, sharp corners, thin structures, cavities, pipelines and use of multi-materials. Also a new mold is needed for each product in the casting method and the mold costs are quite high. In additive production method, no mold is needed. Design can be produced at any time. When it comes to the production of a small number of special parts, faster production is achieved compared to the casting method. Therefore, present study aims to design and produce a multi-material $3 \mathrm{D}$ printer capable of printing non-conductive and conductive rapidly curing silicone that can be used in soft robotics and medical simulators. The electrical conductivity was achieved by mixing silicone and graphite powder. The parts in the printer are also produced by the additive manufacturing. Test pieces were printed using the produced 3D printer. Specific tests on produced parts produced have been carried out to determine mechanical and electrical properties. Technical data such as strength, elasticity, electrical conductivity have been obtained.
\end{abstract}

Keywords: Soft Robotics. Additive Manufacturing. 3D Printers. Multi-Material Printing. Conductive silicone printing

\section{INTRODUCTION}

Soft robots are a variation of robots that can imitate movements of living things and are produced from suitable materials. The branch of science dealing with such robots is called soft robotics. It determines the compatibility of soft robot systems, their flexibility, which constantly and frequently respond and undergo local deformation. Flexible robots can be used in areas that are restricted and difficult to work, unlike conventional robots. Main components of soft robots are sensors and actuators. Sensors detect and react to physical factors such as heat, motion, humidity, pressure. An actuator is a machine element that moves or controls a system or mechanism. Examples of actuators and sensors used in soft robotic systems are shown in Table 1.

Table 1. Examples of actuators and sensors

\begin{tabular}{|c|c|}
\hline Actuators & Sensors \\
\hline Fiber-Reinforced Actuators [12] & Egain Sensors [21] \\
\hline Pneumatic Artificial Muscles [13] & TakkTile Sensors [22] \\
\hline SDM Fingers [14] & Smart Braids Sensors [23] \\
\hline Dielectric Elastomer Actuators [15] & TacTip Sensors [24] \\
\hline Combustion-Driven Actuators [16] & Pneumatic Sensor [25] \\
\hline Manipulator [17] & Textile Silicone Hybrid Sensor [26] \\
\hline Soft-Bending Actuators [18] & \\
\hline Soft Grippers [19] & \\
\hline PneuNets Bending Actuators [20] & \\
\hline
\end{tabular}


Traditionally silicone soft robots are produced by the casting method. A mold is needed for each part. Since the produced molds have a limited lifespan, new ones must produce periodically. Mold production is a costlier and laborious process than the production of the part. This traditional production method has difficulties in the production of complex geometries such as, sharp corners, thin structures, cavities, pipelines and use of multi-materials. Also a new mold is needed for each product in the casting method and the mold costs are quite high. The production of objects designed by a virtual environment in a 3D limited space layer by layer is called additive manufacturing [5]. The usage areas of 3D printers are increasing today, as they can be integrated into almost every field. As a result, various printing technologies have emerged. These printing types can be given as selective laser sintering (SLS), direct ink writing (DIW), shape deposition modeling (SDM), fused deposition modeling (FDM), inkjet printing. SDM is a robust free-form manufacturing process; it is built from top to bottom, rather than removing excess material from specific objects. It is achieved by layering the lining material and the required finished material [33].

Detailed examination of the economics of additive manufacturing (SLS) by Atzeni and Salmi [27] show that after a certain threshold additive manufacturing will be cheaper than the traditional manufacturing method. In additive production method, no mold is needed. Design can be produced at any time. When it comes to the production of a small number of special parts, faster production is achieved compared to the casting method. The lack of need for using a core in additive manufacturing decreases the labor time and also helps to produce parts that cannot be achieved by casting method. Many studies have been conducted on flexible robots from past to present. Detailed examination of design, fabrication, and control of the soft robots by Daniela and Micheal [4] showed that soft robots could be applied in various areas of use. Soft robots easy integration with body tissues help people in difficult working conditions. Flexible robots are suitable for use in applications such as biomedical applications, exploration missions in areas that are difficult to move. Apart from these, there is more than one type of soft robot according to their usage areas. Examples of robotic muscles, climbing, edible robots, wearable robots, prosthetic robots, and flexible gripper robots are soft robots. Robotic muscles are designed to mimic the muscles in the human body. Climbing robots have potential applications ranging from building inspection and maintenance to search and rescue missions. A version of the soft climbing robot, like a caterpillar, has a curved design that allows it to climb large structures. Edible robots are biodegradable and can safely deliver drugs to different parts of the body. Because wearable robots can imitate the human body's natural movements, they can be applied to physically rehabilitated patients [4]. Kai et al. [3] pointed out how a soft gripper uses prosthetic robots at the end of the prosthesis to grasp objects more finely and accurately for people with missing limbs. Another example of soft robotic is carried out by Schumacher et al. [1] in which is a heart-shaped pump robot operating at 500 watts and 10000 combustion cycles. Another example of what is meant by Giovanni Rateni, et al. [2] is a gripper design using soft elastomers.

As in the examples given, soft robots' types and usage areas are increasing day by day. In light of these developments, soft robots need to have more complex structures such as, sharp corners, thin structures, cavities, pipelines. These complex structures and the functions they supply can be obtained by using additive manufacturing. An example of a 3D printer made by Gul et al. [6] for soft robotics. The study of Muth et al.[7] is an excellent example of the printing of strain sensors within highly stretchable elastomer. In the work of Dilibal et al. [28] three pneumatic soft actuators are produced with different geometries using TPU and additive manufacturing. Actuators are tested and compared with different finite element methods. Using TPU material Dilibal et al [29] have created soft robotic gripper with embedded sensors using FDM printing method. Detailed examination of Direct 3D printing of silicone elastomer soft robots and their performance comparison with molded counterparts by Yirmibesoglu, et all (2019) [30] showed that soft robots could be manufactured with different methods. Another example of a 3D printer made for soft robotics is the study carried out by Georgopoulou et al. (2021) [31] in which A Sensorized Soft Pneumatic Actuator Fabricated with Extrusion-Based Additive Manufacturing. In this study, two different techniques were used for two different materials. For the conductive material, a filament was produced using carbon powder and printed with the FDM technique. For the insulating material, the silicone material was printed by the extrusion method. 
Unique printing materials $[8,9]$ are needed to produce soft robotic elements with $3 \mathrm{D}$ printers. These unique printing materials are classified as smart materials. Smart materials can fulfill the desired functions by responding to the warnings originating from the environment. These external effects can be $\mathrm{pH}$, mechanical, chemical, optical, moisture, thermal and electric fields, or magnetic fields. Because of these features, smart materials make essential contributions to the production of soft robotic elements with $3 \mathrm{D}$ printers. $4 \mathrm{D}$ printing is the name given to the phenomenon of $3 \mathrm{~d}$ printing that occurs under certain conditions. This phenomenon occurs when a structure produced with smart materials reacts to ambient conditions and performs functions determined by this reaction [10].

This study aims to design and produce a multi-material 3D printer capable of printing non-conductive and conductive rapidly curing silicone that can be used in soft robotics and medical simulators. The electrical conductivity was achieved by mixing silicone and graphite powder. The parts in the printer are also produced by the additive manufacturing. Test pieces were printed using the produced $3 \mathrm{D}$ printer. Specific tests on produced parts produced have been carried out to determine mechanical and electrical properties. Technical data such as strength, elasticity, electrical conductivity have been obtained.

\section{3D PRINTER DESIGN FOR SOFT ROBOTIC ELEMENTS}

\subsection{Design of the 3D Printer}

Proposed 3D printer consists of multiple flow lines of conductive silicone, silicone and silicone agent. They converge in the mixing chamber of the printer as shown in Figure 1. Mixing chamber mix materials homogeneously with each other depending on the type of the material to be printed. The 3D printer has a Cartesian shape with three axes motion. The print bed is heated so that the printed silicone adheres better to the print bed. Technical information of 3D printer is given in Table 2.

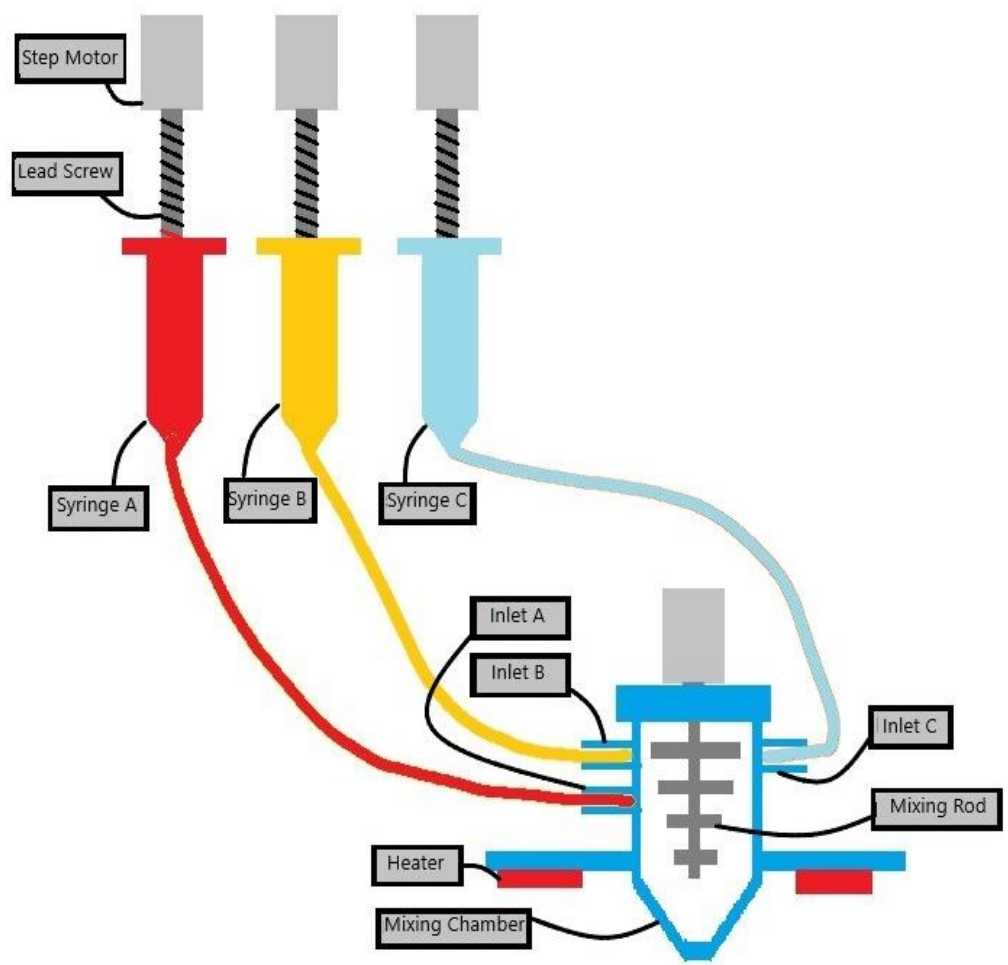

Figure 1. General system schematic 
Table 2. General information of 3D printer

\begin{tabular}{|l|l|}
\hline General Dimension & $580 \times 490 \times 560 \mathrm{~mm}$ \\
\hline Printer Bed Dimension & $300 \times 200 \mathrm{~mm}$ \\
\hline Printing Area Dimension & $300 \times 200 \times 200 \mathrm{~mm}$ \\
\hline Motor Type and Quantity & Nema 17 Step Motor, 6 Pieces \\
\hline Vertical Movement & Threaded Rods \\
\hline Horizontal Movement & Pulley System \\
\hline Motherboard & Re-ARM with RAMPS 1.4 Motherboard \\
\hline Software & Repetier Host \\
\hline
\end{tabular}

Extrusion system consists of two modules parts such as syringe pump and the mixer. The syringe pump is shown in Figure 2. The syringe system is located on the top of the 3D printer. The syringe system consists of three separate syringe tubes with pistons attached to threaded rods that are controlled by Nema 17 motors. The transformed linear motion is transferred to the pistons in the tube, and the movement of the silicone is provided. Silicone is transmitted to the mixing chamber through the pipes. In addition, the tubes in the syringe part serve as a reservoir for the silicone and other materials used in the $3 \mathrm{D}$ printer. Each syringe has an equal volume and a storage capacity of $78 \mathrm{ml}$. It provides insulation against moisture, air, and heat to silicone. The storage conditions of the syringe prevent the stored silicone from curing. In this way, the printing and storage life of the used silicone increases significantly. Previously prepared materials can be easily refilled into the tubes by the easy assembly provided by the syringe mechanisms. The assembled image of the mixing chamber mechanism is given in Figure 3.

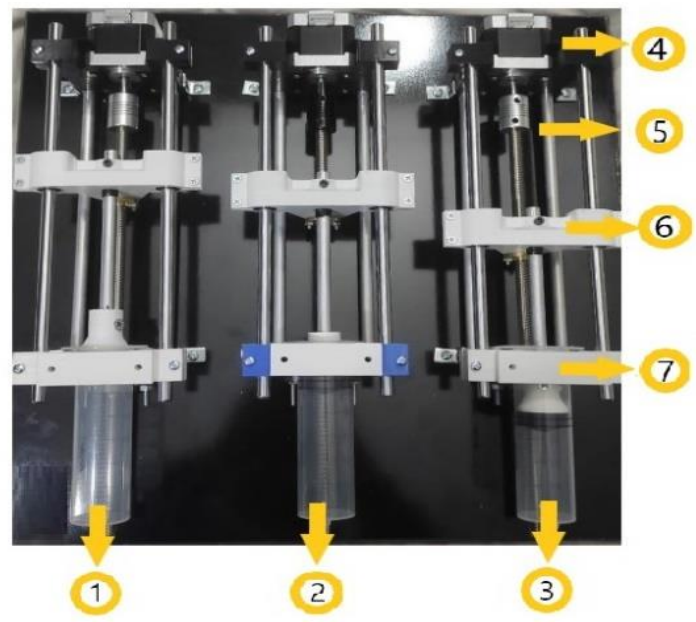

Figure 2. Syringe System, The numbers 1, 2 and 3 in the picture are syringes. It is where the mixture to be printed from the 3D printer is stored. Number 4 in the image is the Nema17 motor that will move the material from the syringe. The number 5 in the picture is the threaded rod that converts the rotational motion obtained from the motor into linear motion. Numbers 6 and 7 in the picture are the parts that restrict the movement of the syringe.

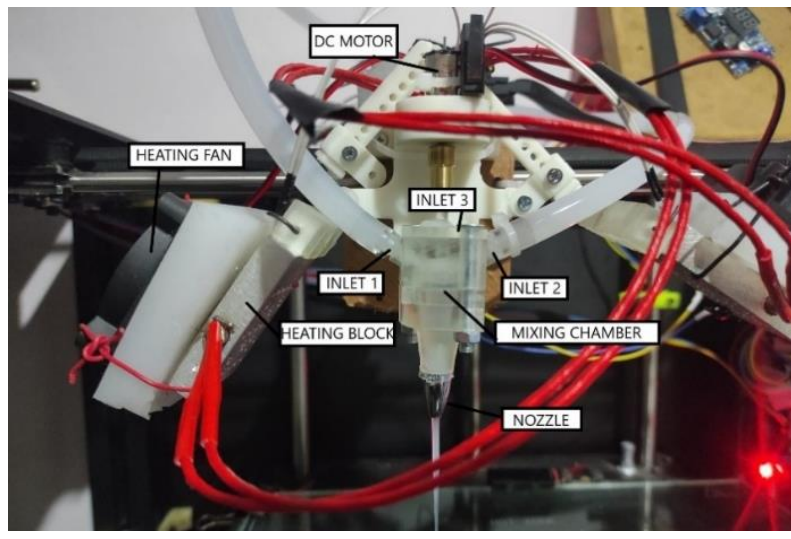

Figure 3. Extruder mechanism picture 
Three inlets on the mixing chamber connected to a separate syringe with different material. Materials entering the mixer through separate inlets are dynamically mixed with the blade mechanism. Rotational motion is transmitted by de motor. The characteristics of the blade mechanism, such as the speed, the number of teeth, and the dimensions, are adjusted so that the materials are mixed homogeneously. In addition, gear blades are placed at an angle of 45 degrees. Due to the design and movement of the blade mechanism, pressure builds up on the mixture. The resulting pressure and the rotational movement of the mixer enable the mixed material to move in both radial and axial directions, and the mixer mechanism transmits the extrusion motion of the syringe pumps. Two heating blocks at the outlet of the mixer mechanism are used to cure the silicone. Heating blocks are located at the bottom of the mixer on the right and left sides to shorten the production time. The image of the printer while printing is given in figure 4.

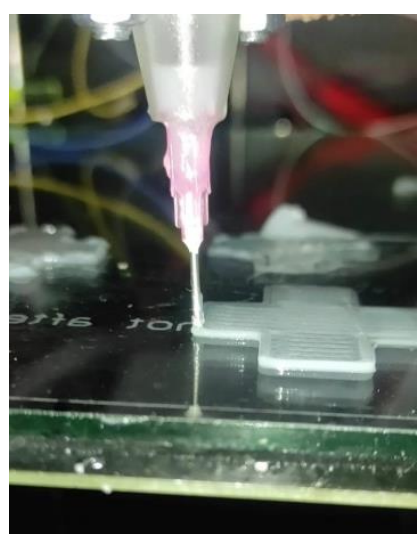

Figure 4. 3D printer while operating

\subsection{Methodology}

Three different materials used are Dragon Skin ${ }^{\mathrm{TM}} 10$ VERY FAST make-up silicone, thixotropic agent, and graphite powder. Dragon Skin ${ }^{\mathrm{TM}}$ silicones are fast-curing liquid silicone compound often used in film sets to create skin effects and other special effects. Dragon Skin TM is in the form of two components $\mathrm{A}$ and B. These are used by forming mixtures in appropriate proportions. Dragon Skin ${ }^{\mathrm{TM}}$ silicone mixture can be used between $-53^{\circ} \mathrm{C}$ and $+232^{\circ} \mathrm{C}$. The shore value of silicone is $10 \mathrm{~A}$ in ASTM D-412 [11] test standards. Aa thixotropic agent was used to densify the silicone. Silicone has been more suitable for a 3D printer with the thixotropic agent. After obtaining printable silicone, graphite powder was used to obtain conductivity. The mixing ratios of the materials to obtain two types of silicon, conductive and non-conductive are shown in Table 3.

Table 3. Mixture percentage

\begin{tabular}{|l|l|l|l|}
\hline & Dragon Skin A & Dragon Skin B & Grafite Powder \\
\hline Non-Conductive Silicone & $50 \%$ & $50 \%$ & $0 \%$ \\
\hline Conductive Silicone & $48.7 \%$ & $48.7 \%$ & $2.6 \%$ \\
\hline
\end{tabular}

At the beginning of the printing process, the 3D Repeiter software with slicer separates the designed part into layers. The software determines the conductive and non-conductive parts of each layer according to the color of the drawn parts. According to these determined regions, the 3D printer sets which syringes will work. At each print just two materials come to the mixer section of the 3D printer using hoses and mixed homogeneously in the mixer and get out due to the pressure supply from the syringe pumps. When switching materials, a certain amount of material left in the mixer from the previous operation is disrupting the design. Therefore, the material transition is applied. Between the material passes, extruder is sent to an empty corner to clean the material remaining in the mixer and discharges the unwanted material inside. This operation is repeated for each material pass.

Curing is the phenomenon of silicone in liquid form reaching its final hardness upon exposure to specific environmental conditions. The curing process of the silicone used in the project starts at room temperature $\left(73^{\circ} \mathrm{F} / 23^{\circ} \mathrm{C}\right)$. Curing time in room temperature exceeds 30 minutes. Heating blocks, one on the right and one on the left of the mixer are placed for the curing process in the $3 \mathrm{D}$ printer. 
Heating blocks reach a temperature of $80^{\circ} \mathrm{C}$. With the curing technique used, the curing of a single layer was shortened to 30 seconds. In addition to the heater blocks, the printing bed of the $3 \mathrm{D}$ printer is heated, contributing to the curing of the silicone.

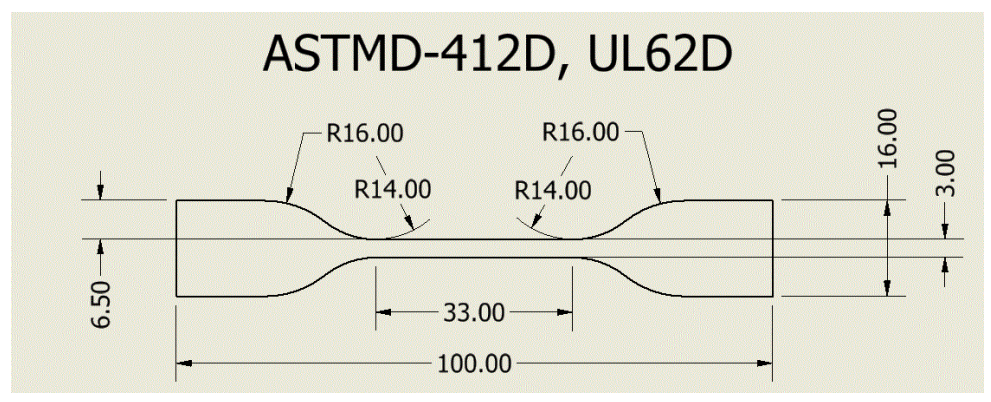

Figure 1. Specimen dimensions ASTMD

For the tensile test, a dumbbell test piece in accordance with ASTM D412 standard ( Figure 5) was designed. The tensile test has been done using a printed test specimen. As a result of this test, the strength values of the piece were calculated. One of the test specimens is shown in Figure 6 . The test piece is $100 \mathrm{~mm}$ long and $16 \mathrm{~mm}$ wide. The throat of the test piece is $3 \mathrm{~mm}$ wide and $33 \mathrm{~mm}$ long. There is fillet in $16 \mathrm{~mm}$ and $14 \mathrm{~mm}$ diameter corners to prevent stress concentration. Also, the test piece is printed with $3 \mathrm{~mm}$ thickness.

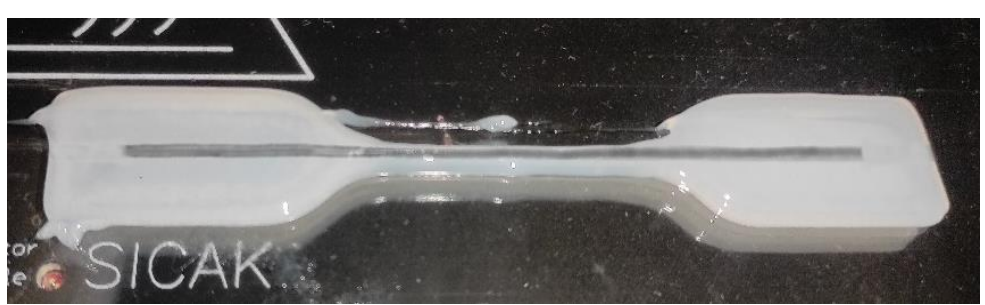

Figure 2. Printed part

\section{TESTS AND RESULTS}

\subsection{Tensile Test}

3D printed parts has a shore value of $10 \mathrm{~A}$ and were subjected to a tensile test according to ASTM D412 standards. The tensile has been done with several steps. These steps are, reaching the specified elongation within $15 \mathrm{sec}$, holding the specimen for $10 \mathrm{~min}$ with desired elongation, release test specimen quickly without any snap back, and rest the test specimen for $10 \mathrm{~min}$. The same test was repeated 5 times to find a mean results. Results are given in Table 4.

Table 4. Tensile test results for 3DIW parts

\begin{tabular}{|c|c|c|c|c|c|}
\hline 3D Printed Part & Test \#1 & Test \#2 & Test \#3 & Test \#4 & Test \#5 \\
\hline $\begin{array}{c}\text { Tensile Strength } \\
\text { (KPa) }\end{array}$ & 3200 & 3182 & 3238 & 3220 & 316 \\
\hline \% 100 Modulus (KPa) & 151 & 148 & 155 & 152 & 147 \\
\hline $\begin{array}{c}\text { Maximum Elongation } \\
\text { (mm) }\end{array}$ & 498 & 494 & 496 & 502 & 480 \\
\hline $\begin{array}{c}\text { Elongation @ Break } \\
(\%)\end{array}$ & 498 & 494 & 496 & 502 & 480 \\
\hline
\end{tabular}

Finite element analysis has been done to support the calculations. The material properties for finite element analysis are set manually. The hardness of the material is set to 10 according to the Shore A value, tensile strength 32.75 bar, $100 \%$ modulus 1.51 bar. Detailed material properties are given in Table 5 and results of the finite element analysis is shown in Table 6. 
Table 5. Material properties

\begin{tabular}{|c|c|}
\hline Property & Value \\
\hline Specific weight & $1.07 \mathrm{~g} / \mathrm{cc}$ \\
\hline Specific Volume & $1.63 \mathrm{~m} 3 / \mathrm{kg}$ \\
\hline Shore A Hardness & 10 \\
\hline Tensile Modulus & $32.75 \mathrm{Bar}$ \\
\hline $100 \%$ Modulus & $1.51 \mathrm{Bar}$ \\
\hline Viscosity & $23000 \mathrm{cps}$ \\
\hline
\end{tabular}

The test piece was subjected to a tensile force of $100 \mathrm{~N}$ by being fixed at one end in the analysis. The results are given in Table 6 .

Table 6. Finite element analysis results

\begin{tabular}{|c|c|c|c|c|}
\hline Results & Minimum & Maximum & Unit & Time(s) \\
\hline Total Deformation & 0 & $2.9015 \mathrm{e}-006$ & $\mathrm{~m}$ & 1 \\
\hline $\begin{array}{c}\text { Maximum Shear } \\
\text { Stress }\end{array}$ & $3.724 \mathrm{e}+005$ & $6.235 \mathrm{e}+006$ & $\mathrm{~Pa}$ & 1 \\
\hline $\begin{array}{c}\text { Maximum Shear } \\
\text { Elastic Strain }\end{array}$ & $4.8411 \mathrm{e}-006$ & $8.1055 \mathrm{e}-005$ & $\mathrm{~m} / \mathrm{m}$ & 1 \\
\hline
\end{tabular}

According to the test results, the printed test piece can stretch 4.94 times its own length. At the same time, due to the high strength values, it has been observed that the printed soft robotic elements can maintain their form during motion.

\subsection{Conductivity Test}

One of the qualities required for sensor production is electrical conductivity. For this reason, the electrical conductivity of the parts produced by 3D printer were tested in the second stage of the tests. In order to perform the electrical conductivity test, the printed geometry with the conductive material was determined. Using this geometry, the test specimens were printed. The required coefficients to obtain the resistance of the conductive material were calculated over the determined geometry. Our test specimen has a length of $80 \mathrm{~mm}$, width of $1 \mathrm{~mm}$ and thickness of $3 \mathrm{~mm}$ electrically conductive zone. According to these dimension, $\mathrm{A} / \mathrm{L}$ value of conductive zone is $\left(3.10^{-5}(1 / \mathrm{m})\right)$. After the necessary calculations, the produced part was accepted as a resistor added to the system. A voltage difference of certain magnitudes was applied to the system using a calibrated voltage source. While the circuit is under load, the amount of current passing through the conductive region was measured with the help of an ampere meter. The resistance value was calculated using the current values obtained. By using the calculated resistance and geometric values, the resistivity value of the conductive material was found. Detailed results are given in table 6.

Table 4. Conductivity results of 3DIW parts

\begin{tabular}{|l|l|l|l|l|l|}
\hline 3D Printed Part & Test \#1 & Test \#2 & Test \#3 & Test \#4 & Test \#5 \\
\hline Voltage & $5 \mathrm{~V}$ & $7 \mathrm{~V}$ & $6 \mathrm{~V}$ & $8 \mathrm{~V}$ & $4 \mathrm{~V}$ \\
\hline Ampere & $0.8 \mathrm{~A}$ & $1.14 \mathrm{~A}$ & $0.95 \mathrm{~A}$ & $1.33 \mathrm{~A}$ & $0.62 \mathrm{~A}$ \\
\hline Resistance & $6.25 \Omega$ & $6.14 \Omega$ & $6.32 \Omega$ & $6.02 \Omega$ & $6.45 \Omega$ \\
\hline Resistivity $\left(\frac{\boldsymbol{A}}{\boldsymbol{L}} \boldsymbol{\rho}\right)$ & $\begin{array}{l}1.88 \times 10^{-4} \\
\Omega m\end{array}$ & $\begin{array}{l}1.84 \times 10^{-4} \\
\Omega m\end{array}$ & $1.89 \times 10^{-4} \Omega m$ & $1.8 \times 10^{-4} \Omega m$ & $1.94 \times 10^{-4} \Omega m$ \\
& & & \\
\hline
\end{tabular}

As a result of the tests and calculations, the average electrical resistivity value was obtained as $1.87 \times 10^{-4} \Omega \mathrm{m}$ at room temperature. The average values of the conductors are between $10^{-2} \Omega \mathrm{m}$ and $10^{-8} \Omega \mathrm{m}$. The electirical resistivity value of graphite at room temperature is $1 \times 10^{-5} \Omega \mathrm{m}$. By looking at these values, it is seen that the conductive silicone mixture can easily transmit the given current. 


\section{DISCUSSION}

The findings of the use of silicone type material for $3 \mathrm{~d}$ printing of soft robotic elements are consistent with those of Yirmibesoglu, et al. [30], The main difference of this study is that it can print conductive silicon simultaneously with non-conductive silicon. These findings further support the idea of $3 \mathrm{~d}$ printing of silicon materials as in the study of Georgopoulou et al. [31] main difference in our study is that it is conductive material is embedded by extrusion of conductive silicon instead of printing with FDM. The results of the study shows similar results for the test of dumbbells using ASTM D-412 standard as carried by Miriyev et al [32]. When the two studies are compared, it can see that, values are found to be a match with each other. As a result of the two studies, it has been seen that the silicone materials printed with $3 \mathrm{D}$ printers have high strength. In addition to these properties, they were able to preserve their elastic properties. Because the 3 DIE materials preserve these properties, it has been seen that 3D printers can be used in soft robotic applications.

\section{CONCLUSION}

At the end of this study, a 3D printer and extrusion system is designed and produced to be used for production of soft robotic elements with conductive and non-conductive silicon. The part production time has been improved by more than $40 \%$, with a reduction in curing time. The properties of the test piece taken by our 3D printer have been found to be close to the specified material properties. Another result of the study showed that silicone in the syringes of the 3D printer did not cure over time, and curing started at the exit of the syringe. These results showed that the designed 3D printer and extrusion system is capable of printing soft robotic elements.

\section{ACKNOWLEDGEMENT}

This project is funded by Tubitak 2209-b with application I.D. 1139B412001047.

\section{REFERENCES}

1. Schumacher, M., Loepfe, M., Fuhrer, R., Grassa, R.N., Stark, W.J., “3D printed lost-wax casted soft silicone monoblocks enable heart-inspired pumping by internal combustion”, RSC Advances, Vol. 4, Issue 31, Pages 16039-16042, 2014.

2. Rateni, G., Cianchetti, M., Ciuti, G., Menciassi, A., Laschi, C., "Design and development of a soft robotic gripper for manipulation in minimally invasive surgery: a proof of concept", Meccanica, Vol.50, Pages 2855$2863,2015$.

3. Yap, H. K., Ng, H. Y., Yeow, C. H., "High-force soft printable pneumatics for soft robotic applications.”, Soft Robotics, Vol. 3, Issue 3, Page 144-158, 2016.

4. Rus, D., Tolley, M. T., "Design, fabrication and control of soft robots”, Nature 2015, Pages 467-475, 2015.

5. Gibson, I., Rosen, D., Stucker, B., "Additive manufacturing technologies: 3D printing, rapid prototyping, and direct digital manufacturing", 2nd edn. Springer, New York, 2015.

6. Gul, J. Z., Rehman, M. M., Siddiqui, M. M., Shah, G. U., Kim, I., Choi, K. H., “3D printing for soft roboticsa review", Science and technology of advanced Materials, Vol. 19, Issue 1, Pages 243-262, 2018.

7. Muth, J.T., Vogt, D.M., Truby, R.L., Mengüç, Y., Kolesky, D. B., Wood, R. J., Lewis, J. A., “3D Printing Embedded 3D Printing of Strain Sensors within Highly Stretchable Elastomers”, Adv. Mater., Vol. 26, Issue 36,2014

8. Zarek, M., Layani, M., Cooperstein, I., et al., "3D printing of shape memory polymers for flexible electronic devices”, Adv. Mater., Vol. 28, Issue 22, 2016.

9. Yang, Y., Chen, Y., Wei, Y., et al, "3D printing of shape memory polymer for functional part fabrication", Int J Adv Manuf Ischnol, Vol.84, Pages 2079-2095, 2016.

10. Akhras, G., "Smart Materials and Smart Systems for the Future”, Canadian Military Journal, Vol.1, Issue 3, Pages 24-31, 2000 
11. ASTM D412-16e1, Standard Test Methods for Vulcanized Rubber and Thermoplastic Elastomers-Tension, ASTM International, West Conshohocken, PA, 2016,

12. Bishop-Moser, J., Kota, S., "Design and Modeling of Generalized Fiber-Reinforced Pneumatic Soft Actuators”, IEEE Transactions on Robotics, Vol. 31, Issue 3, Pages 536-545, 2015

13. Daerden, F., Lefeber, D., "Pneumatic artificial muscles: Actuators for robotics and automation", Eur. J. Mech. Environ. Eng., Vol. 47, Page 11-21, 2002.

14. Dollar, A. M., Howe, R. D., "The highly adaptive SDM hand: Design and performance evaluation", The International Journal of Robotics Research, Vol. 29, Issue 5, Pages 585-597, 2010.

15. Kofod, G., "Dielectric elastomer actuators", Ph.D. Thesis, The Technical University of Denmark, Lyngby, 2001

16. Funk, R., Parekh, D., Crittenden, T., Glezer, A., "Transient Separation Control using Pulse Combustion Actuation", 1st Flow Control Conference, Pages 24-26, St. Louis, Missouri, 2002.

17. Immega, G., Antonelli, K., "The KSI tentacle manipulator", Proceedings of 1995 IEEE International Conference on Robotics and Automation 1995, Pages 3149-3154, Nagoya, Japan, 1995.

18. Polygerinos, P., Wang, Z., Overvelde, J. T., Galloway, K. C., Wood, R. J., Bertoldi, K., \& Walsh, C. J., "Modeling of soft fiber-reinforced bending actuators", IEEE Trans. Robot, Vol.31, Issue 3, Pages 778-789, 2015.

19. Wang, Z., Chathuranga, D.S., Hirai, S., "3D printed soft gripper for automatic lunch box packing", IEEE International Conference on Robotics and Biomimetics (ROBIO), Pages 503-508, Qingdao, China, 2016.

20. Souhail, A., Vessakosol P., "PneuNets bending actuator design and fabrication using low cost silicones", TSME-ICoME. ACM Press, 2018.

21. Lu, S., Chen, D., Hao, R., Luo, S., \& Wang, M., "Design, fabrication and characterization of soft sensors through EGaIn for soft pneumatic actuators", Measurement, Vol. 164, 2020.

22. Jentoft, L. P., Tenzer, Y., Vogt, D., Liu, J., Wood, R. J., Howe, R. D., "Flexible, Stretchable Tactile Arrays From MEMS Barometers", The 16th International Conference on Advanced Robotics, Montevideo, Uruguay, 2013.

23. Felt, W., Lu, S., Remy, C.D., "Modeling and Design of "Smart Braid" Inductance Sensors for FiberReinforced Elastomeric Enclosures", IEEE Sensors Journal, Vol. 18, Issue 7, Page 2827-2835, 2018.

24. Ward-Cherrier, B., Pestell, N., Cramphorn, L., Winstone, B., Giannaccini, M. E., Rossiter J., et al., "The TacTip Family: Soft optical tactile sensors with 3D-Printed biomimetic morphologies", Soft Robotics, Vol. 5, Issue 2, Pages 216-227, 2018.

25. Yang, H., Chen, Y., Sun, Y., Hao, L., "A novel pneumatic soft sensor for measuring contact force and curvature of a soft gripper", Sens. Actuat., Vol. 266, Pages 318-327, 2017.

26. Atalay, A., Sanchez, V., Atalay, O., Vogt, D., M., Haufe, F., Wood, R. J., Walsh, C. J., "Batch Fabrication of Customizable Silicone-Textile Composite Capacitive Strain Sensors for Human Motion Tracking", Adv. Mater. Technol., Vol.2, Issue 9, 2017.

27. Atzeni, E., Salmi, A. "Economics of additive manufacturing for end-usable metal parts", Int J Adv Manuf. Technol., Vol.62, Pages 1147-1155, 2012.

28. Dilibal, S., Sahin, H., \& Celik, Y., "Experimental and numerical analysis on the bending response of the geometrically gradient soft robotics actuator", Archives of Mechanics, Vol.70, Issue 5, Pages 391-404, 2018. 
29. Dilibal, S., Sahin, H., Danquah, J. O., Emon, M. O. F., Choi, J. W., "Additively Manufactured Custom Soft Gripper with Embedded Soft Force Sensors for an Industrial Robot", International Journal of Precision Engineering and Manufacturing, Vol.22, Issue 4, Pages 709-718, 2021.

30. Yirmibesoglu, O. D., Morrow, J., Walker, S., Gosrich, W., Cañizares, R., Kim, H., Menguc, Y., "Direct 3D printing of silicone elastomer soft robots and their performance comparison with molded counterparts", IEEE International Conference on Soft Robotics (RoboSoft), Pages 295-302, Livorno Italy, 2018.

31. Antonia G., Lukas E., Bram V., Frank C., "A Sensorized Soft Pneumatic Actuator Fabricated with ExtrusionBased Additive Manufacturing," Actuators, Vol.10, Issue 5, 2021.

32. Miriyev A., Xia B., Joseph J.C., Lipson, H. "Additive Manufacturing of Silicone Composites for Soft Actuation" 3D Print Addit. Manuf., Vol.6, Issue 6, 2019.

33. Kiraz C., Sezer H., Şahin İ., "Kuyumculuk sektöründe 3b baski tasarim özgürlüğünden faydalanmaya ilişkin bir perspektif", International Journal of 3D Printing Technologies and Digital Industry, Vol.2, Issue 2, Pages 46-58, 2018. 